perifèria

Número 14, abril 2011

www.periferia.name

\title{
"El trabajo de un antropólogo termina en el momento en que este es como el otro"
}

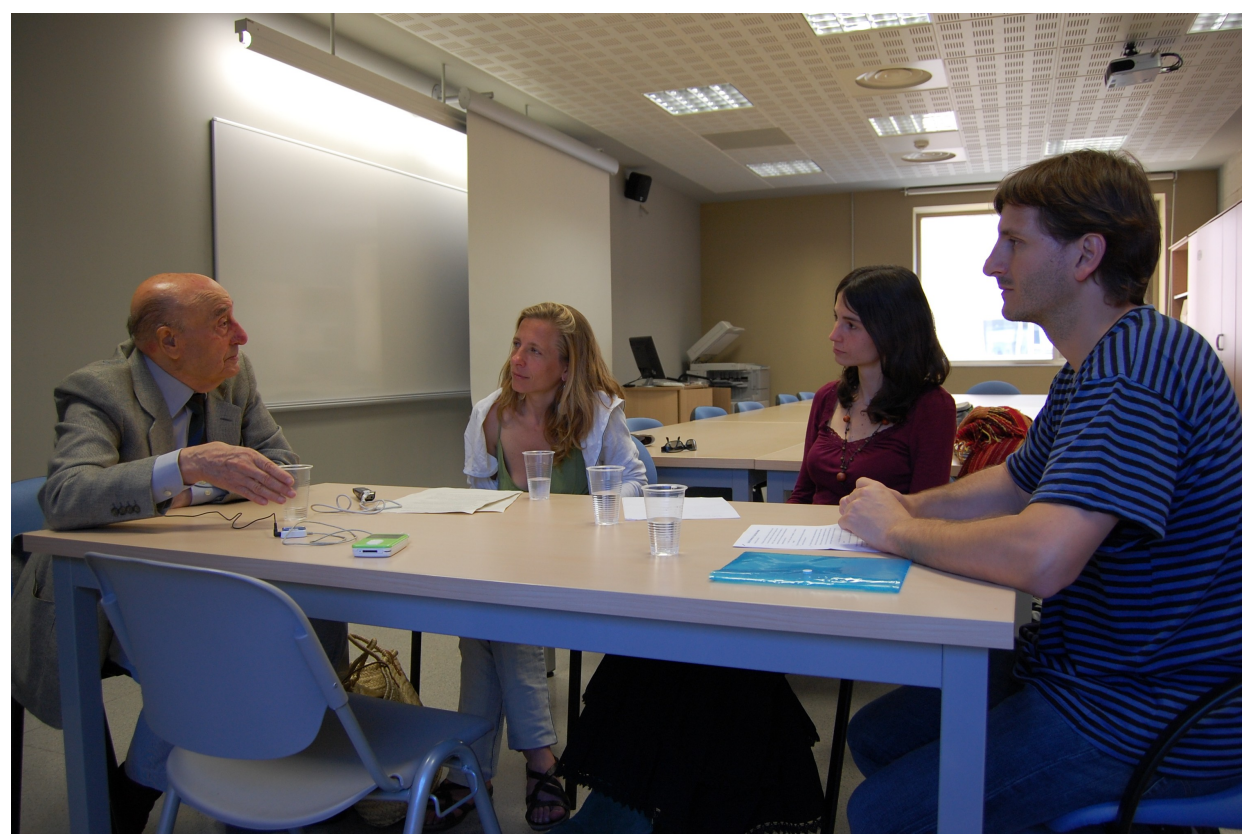

(Fotografías: Montserrat Clua)

\section{Entrevista a Claudi Esteva Fabregat, antropólogo}

Autores: Brufau, Joana; Permanyer, Maria; Zulet, $\mathrm{Xavi}^{1}$

Universitat Autònoma de Barcelona²

Directora: Montserrat Clua Fainé

\section{Resumen:}

El Projecte Entrevistes presenta, por fin, la que tendría que haber sido la primera entrevista de la serie: la realizada a Claudi Esteva Fabregat, el iniciador de la

\footnotetext{
${ }^{1}$ Autores de la traducción al castellano: Joana Brufau, Montserrat Clua y Xavi Zulet.

${ }^{2}$ Enviar correspondencia a: Montserrat Clua, Montserrat.clua@uab.cat
} 
perifèria

Número 14, abril 2011

www.periferia.name

antropología sociocultural en España. A lo largo de la conversación el profesor Esteva repasa toda su trayectoria, desde su juventud (marcada por la guerra civil) hasta la antropología de hoy, citando antiguos maestros, clásicos de la antropología y discípulos que siguieron su camino. La entrevista da las claves que explican porque la antropología española es como es y muestra los constantes intercambios humanos e intelectuales que se han dado (y que Esteva todavía mantiene) entre Barcelona y México. A su vez, la entrevista es un emocionante relato de la dura experiencia de los intelectuales catalanes exiliados en México, el paso de Esteva por la ENAH, y las dificultades del retorno a la España franquista de 1956. La entrevista finaliza con sus reflexiones sobre cómo es y cómo cree él que debe ser la disciplina.

Pregunta: Como futuros antropólogos, o por lo menos, como futuros licenciados en antropología, nos hace mucha ilusión poder hablar con usted, uno de los fundadores de nuestra disciplina en Catalunya y en España. Como usted vive en México, para nosotros es un privilegio poder aprovechar su visita a nuestro país para entrevistarle. Le estamos muy agradecidos de que nos haya podido dedicar este tiempo.

Claudi Esteva: Al contrario, estoy muy contento de estar con ustedes.

P: En alguna ocasión usted ha manifestado que el estudio antropológico le permitió afrontar, desde una nueva perspectiva, las inquietudes surgidas a raíz de la experiencia de la guerra y del exilio. Si le parece empezamos hablando de su infancia y juventud la cual, a causa de la Guerra Civil, tuvo que vivir exiliado en México.

C.E.: Yo empecé a estudiar antropología a partir del año 1947, y llegué a México en el año 1939. Precisamente, en junio del año pasado [2009] se realizó lo que allí en México llaman un Evento, para celebrar la llegada del SINAIA, el primer barco de exiliados que procedía de Francia y que entró en México.

El 13 de Junio de 1939 llegué a México con el primer barco de exiliados que salía de Francia. Éramos 1.800 aproximadamente y muchos proveníamos del campo de concentración de Saint Cyprien. Cuando llegué al campo de concentración francés, estuvimos rodeados todos nosotros por soldados del Senegal y fuimos objeto de constantes humillaciones. Yo tenía 20 años. Estuve en el campo de concentración 100 días. Previamente mi tía (la hermana de mi padre), que vivía en Marsella en donde tenía una fábrica de sombreros, un día me vino a ver al campo de concentración para reclamarme, pero yo me negué rotundamente a abandonar a mis compañeros. Escribí, junto a otro compañero, al Comité Británico de ayuda a 


\section{perifèria}

Número 14, abril 2011

www.periferia.name

España, que estaba dirigido por la duquesa de Atholl. ${ }^{3}$ Les escribimos porque sabíamos que podían ayudarnos. De hecho, a mi me podían ayudar bastante porque yo nací en Marsella; por lo tanto, podía reclamar la nacionalidad francesa. Que conste que soy francés de cuarenta días, porque mi madre me tuvo en Marsella, pero volvimos a Barcelona pasada la cuarentena que las mujeres cumplían en aquella época.

Inicialmente no nos contestaron pero al cabo de unos meses, debió ser hacia el mes de abril, vino la duquesa de Atholl al campo de concentración y dieron mi nombre. La acompañaban dos intérpretes. Me dijeron que había sido seleccionado, no para ir a Inglaterra (que es lo que pedimos algunos), sino para ir a México. El comité británico de ayuda a España tenía adjudicada una parte del pasaje de aquella primera expedición, donde puede que cupiéramos 30 o 40 exiliados, y que fue pagada en parte por fondos gestionados por la secta religiosa de los cuáqueros.

El 25 de mayo embarcamos, en una noche que recuerdo mucho por la despedida simbólica que les dedicamos a los gendarmes franceses, diciéndoles de todo, porque nos habían tratado muy mal, como a delincuentes. Llegamos a Veracruz, México, el 13 de junio de 1939 y nos encontramos con la sorpresa de que nos recibían como héroes. Me emociono al recordarlo, porque realmente fuimos muy bien recibidos.

Al entrar los exiliados en México nos repartieron por todo el país sugiriéndonos, pero sin imponerlo, que sería bueno que fuéramos a una u otra destinación. Allí tuve, por primera vez, una sensación de gran libertad. Entonces me mandaron al Distrito Federal, en donde cada uno acudía a su organización para tratar con la información que recibíamos de España.

\section{P: Explíquenos como vivió estos primeros años en el exilio, teniendo en cuenta que no sabía cuánto tiempo viviría fuera de Catalunya. ¿Cómo fue integrándose el joven Claudi Esteva en el día a día de su país de acogida?}

C.E.: Teníamos todos la idea en la cabeza de que al cabo de tres meses volveríamos a casa. Es decir, no teníamos una conciencia muy clara de que aquello duraría mucho tiempo. Pensábamos que vendría la guerra, que probablemente la

\footnotetext{
3 Katherine Marjory Murray- Stewart, duquesa de Atholl, fue la primera mujer diputada del Partido Conservador. Luchadora contra los totalitarismos (tanto el soviético como Hitler), participó en el Comité Británico de ayuda a España y en 1937 visitó al Presidente Companys.
} 


\section{perifèria}

Número 14, abril 2011

www.periferia.name

ganaríamos nosotros, los demócratas, y que volvería la República en España. Esta era la convicción, pero estábamos totalmente equivocados, evidentemente.

A los que éramos solteros nos dieron un peso o dos pesos al día, que en aquel tiempo tenían un valor real. Entonces empezamos a conocer el país, cada uno a la suya. Muchos de nosotros tuvimos conflictos con nuestros partidos políticos y se produjo una gran diáspora; unos se separaron, otros continuamos... en fin, todo eso. Hubo un gran periodo de crítica y de crisis ideológica muy fuerte. Muchos de nosotros nos volvimos en aquel momento existencialistas, pues era la moda de los veinte años. Desde el existencialismo hablábamos de la relatividad de las ideas, de los valores... Muchos íbamos por ahí.

Al cabo de un año de estar en México, algunos de nosotros, para poder integrarnos dentro del país, recordábamos cosas. Yo había jugado al fútbol con una peña adscrita a la Unión Deportiva de Sants, el equipo de mi barrio, cuando tenía quince años. A mí me decían “l’Estevet, el noi de Sants". Al llegar a México, cuando bajamos en Veracruz, vino el entrenador del equipo de la cuidad, que es de primera división, y puso un letrero en la plaza de la entrada del muelle en donde decía que el club estaba muy contento de recibir a los futbolistas recién llegados. Un compañero mío vio la pancarta y me animó a participar. A pesar de que durante la guerra ya no había jugado más, y que en aquellos momentos estaba muy esquelético, al día siguiente de haber llegado a México algunos de nosotros realizamos una prueba. Pero la prueba resultó un desastre porque no podíamos ni levantar las piernas. Además, los zapatos que me dieron para jugar a fútbol no eran de mi talla, de modo que las equivoqué todas. Entonces me dijeron que más adelante, cuando me hubiera recuperado, volviera porque habían notado que tocaba bien la pelota. Al cabo de casi un año, formamos un equipo de fútbol que se llamaba "Catalunya", que competía en lo que podríamos llamar el equivalente a una Segunda División $B$ del fútbol mexicano. $Y$ también hicimos un campeonato entre todas las regiones españolas: Asturias, Valencia, Andalucía, Murcia, Madrid... Es un fenómeno muy interesante porque allí todos recuperamos la identidad que nos correspondía dentro de lo que son los episodios de la organización nacional española.

Yo jugaba con el equipo del Catalunya y un buen día nos vio un directivo del club poblano y nos llamó a un par de nosotros (a mí y a un madrileño) para proponernos ir a Puebla, en donde se estaba formando un equipo de fútbol profesional. Nosotros 


\section{perifèria}

Número 14, abril 2011

www.periferia.name

aceptamos porque íbamos muy precarios de ingresos. Allí estuve jugando al fútbol desde el año 1940 hasta el 1945. En 1945 volví a la Ciudad de México, ya para dejar el fútbol.

Entonces, en México D.F. había un extremo diestro del Barcelona que se había quedado en México y que se llamaba Martí Ventolrà, que era muy famoso en aquel tiempo (era internacional) y me propuso dirigir el equipo de fútbol que hasta entonces había entrenado él. Le pregunté cuanto me pagarían y me dijo que 200 pesos, así que acepté porque me irían bien. Cuando empecé a entrenar al equipo ya estaban en la segunda vuelta e iban en séptima posición; pero cuando terminó la liga hice al equipo campeón, de modo que este es un mérito que me lo atribuyo [risas].

\section{P: Allí es donde empezó su interés por la antropología y donde realizó su formación en la Escuela Nacional de Antropología e Historia (ENAH). ¿Por qué buscó respuestas en la antropología y no en otras disciplinas?}

C.E.: En Ciudad de México yo leía mucho, pero en aquel momento no leía antropología, sino a Immanuel Kant. A mí me interesaba mucho el pensamiento, y entre Kant y el existencialismo de Sartre, estuvimos haciendo una combinación extraña, heterogénea. Estos estudios los realicé fuera de la universidad, de modo autodidacta. Hasta que un buen día, caminando por el Zócalo, la plaza principal de la ciudad, vi un cartel en la pared del palacio nacional que decía Escuela Nacional de Antropología e Historia (ENAH) y en donde se anunciaba el inicio de curso, mostrando las ramas en donde se hallaba la antropología: la etnología, la antropología física, la arqueología y la lingüística. Y me dije: "Esto me va bien a mí". Yo estaba pensando en ir a estudiar biología con unos compañeros pero aquello me gustó.

Entonces me dirigí a la escuela y le pedí al secretario información sobre los estudios de antropología. El hombre, de modo muy amable, me explicó todas las posibilidades y me dijo: “En este momento, los que estudian antropología en la Escuela, cuando terminan van a trabajar con los indígenas, porque aquí en México tenemos el problema indígena. Y el gobierno de la República lo que quiere es crear un grupo de antropólogos que puedan elucidar el problema del por qué los indígenas siguen siendo indígenas cuando nosotros les estamos ofreciendo todo". 


\section{perifèria}

Número 14, abril 2011

www.periferia.name

Entonces empecé a pensar también por qué los catalanes quieren seguir siendo catalanes [risas]. Esto me interesó mucho. Hubo una relación de respuesta inmediata, en el sentido de configurar lo que aquel señor me estaba diciendo con mi "problema" catalán. Este punto me interesó mucho.

\section{P: La ENAH fue para usted su primera escuela de formación antropológica, donde conoció figuras relevantes de la disciplina y donde se fue configurando un grupo de debate muy interesante...}

C.E.: Si, allí conocí compañeros míos que entraron por los mismos motivos que yo. Resultó que el grupo catalán dentro de la ENAH era el grupo de extranjeros más numeroso: estaba Molins i Fàbrega, que era el director de La Batalla ; estaba Àngel Palerm que venía del anarquismo, de la CNT; estaba Pedro Armillas, que acabó siendo un gran arqueólogo, uno de los mejores arqueólogos que ha dado México... En fin, había muchos. Formamos un grupo de unos diez.

Después vino Joan Comas que era de las Islas Baleares; también Bosch i Gimpera que era un gran prehistoriador... Estos eran maestros de la escuela. Naturalmente, algunos de ellos no eran antropólogos directamente, pero de todas formas había antropólogos de categoría universal, como Joan Comas que había estudiado en París e hizo una carrera de antropólogo físico. Y Bosch Gimpera que era muy conocido, siendo el secretario del Comité Internacional de Ciencias Antropológicas y Etnológicas. Era un hombre que hablaba indistintamente alemán, italiano, inglés, francés... Era impresionante como cambiaba rápidamente de texto lingüístico y con la facilidad con que lo hacía. Yo nunca he visto una persona tan conocedora. Yo también acostumbraba a acompañar a Lluís Nicolau D'Olwer cuando salía de la escuela e iba a buscar el autobús (porque tenía problemas de visión) y lo acompañaba con mucho respeto. Aquellas eran para nosotros unas personas muy importantes del país.

Y todos nosotros estuvimos formando grupos de discusión. Creamos un seminario, que lo llamábamos El seminario Península. Así hablábamos de una gran confederación de pueblos hispánicos y desde entonces soy confederal, no federal. Esta es mi idea sobre la solución del país. De esta forma integrábamos también a los portugueses, que se peleaban con los gallegos sobre quién era más antiguo en

\footnotetext{
${ }^{4}$ Seminario comunista independiente dirigido por Maurín.
} 


\section{perifèria}

Número 14, abril 2011

www.periferia.name

la Península Ibérica, sobre quién tenía más relevancia histórica... En fin, todo eso. Y este ambiente estaba dentro de otro ambiente, que era el ambiente científico.

En aquel momento, por ejemplo, muchos profesores eminentes de los Estados Unidos estaban dando cursos con nosotros. Estaba George Foster, Isabel Kelly y

Robert Redfield de Chicago... Había un montón. Era uno de los grupos más interesantes de los EUA. Además, estos grupos tenían campamentos dentro del país para estudiar a las sociedades indígenas, que entonces se estudiaban como entidades e identidades etnográficamente únicas. Poco a poco se fue configurando entre nosotros, los que estudiábamos allí, una idea de relativismo cultural que era la idea dominante en aquel momento, aunque es evidente que allí había discusiones dentro de los grupos de estudio.

Estaba el alemán Paul Kirchhoff que en aquel momento era una figura internacional, el que se inventó la noción de "Mesoamérica"; estaba Jacques Soustelle que era del movimiento de De Gaulle, y después, cuando este triunfó en Francia, se fue de ministro allí. Había también gente de Noruega, de Suecia, de los países nórdicos y de diversos países hispanoamericanos, en donde las dictaduras expulsaban cuadros políticos adversarios. $Y$ todo esto configuraba un grupo de proyección internacional que nos daba una antropología de primera línea. Además, había profesores mexicanos que se habían formado en los Estados Unidos, de modo que cualquier asignatura de las que se hacían allí era muy atractiva.

\section{P: ¿Cuáles fueron sus primeros intereses temáticos en antropología y qué paradigmas se le presentaron inicialmente?}

C.E.: Inicialmente en la escuela de antropología me decanté hacia la idea de la antropología física, haciendo muchas asignaturas de este ámbito, porque me interesaba mucho el estudio del porqué de las razas y todo esto. Allí había una asignatura que se llamaba "Raciología", que la impartía Joan Comas y me interesaba mucho. Este y Bosch Gimpera me orientaron mucho. Este último me pidió que no difundiera demasiado su trabajo sobre la etnología de la Península Ibérica, pues estaba convencido de que nosotros sabíamos más que él de etnología (no de prehistoria) y, entonces, le daba vergüenza. Me regaló su libro sobre la etnología de la Península Ibérica ${ }^{5}$ dentro de una especie de proyección prehistórica, de subgrupos que eran distintos... Pero el material que él presentaba era un

\footnotetext{
${ }^{5}$ Ver P. Bosch Gimpera, Etnología de la Península Ibérica, 1932 (reeditada en 2003 en Urgoiti Editores).
} 


\section{perifèria}

Número 14, abril 2011

www. periferia.name

material de formas materiales, es decir, de arqueología. Y, por tanto, le faltaban cosas.

Bosch Gimpera era difusionista y, por tanto, entró en conflicto con los mexicanos, que eran de pensamiento evolucionista. Y se produjo el gran debate entre ambas tradiciones antropológicas. En este debate había la idea de la evolución divergente, que no era unilineal, y discutíamos la idea de si la evolución se concreta desde la perspectiva de la unilinealidad o dentro de la diversidad, de la divergencia. Los mexicanos no querían ser difusionistas por una cuestión de planteamiento nacional. Es decir, ellos habían creado por sí mismos las civilizaciones prehispánicas. Por lo tanto, no tenían ninguna deuda con respecto a Egipto, que venía a ser el centro de la difusión - digámosle moderna - dentro de la época. Y evidentemente nosotros nos planteábamos hasta qué punto había habido allí una influencia del Antiguo Mundo sobre el Nuevo Mundo.

\section{P: Somos conscientes de la diferencia metodológica entre la antropología que hacemos en Europa y la que se hace en América. ¿Nos podría explicar cuáles son los pilares fundamentales del estudio de la antropología americana?}

C.E.: Había un tema de estudio que estaba muy presente en la escuela de antropología americana: el indigenismo. El planteamiento indigenista era muy importante porque nos estaban preparando para cuando acabáramos, inmediatamente ir a hacer trabajo de campo entre grupos indígenas y, así, poder ver las posibilidades de la antropología aplicada.

Entonces también trabajábamos en antropología aplicada. Y hablo no sólo de mi mismo, sino de lo que sería el interior de los grupos que estudiábamos antropología y que éramos "entrenados" para eso. Yo sigo teniendo la convicción de que este es el tipo de entrenamiento. Éramos entrenados en arqueología: hacíamos excavaciones, estudiábamos geología, con los estratos, para ver las correspondencias que tenían estos con las culturas concretas que habían existido. Trabajábamos en antropología física: hacíamos básicamente mediciones. Trabajábamos la etnografía comparada, es decir, la etnología. Y trabajábamos la lingüística, evidentemente. Estas cuatro ramas eran las que configuraban el entrenamiento del antropólogo. Cuando acababas la carrera tenías un equilibrio entre la presencia de la lingüística, de la arqueología, de la antropología física y de la etnología. Y te daban el título en función de las asignaturas que dominaras, de 


\section{perifèria}

Número 14, abril 2011

www.periferia.name

aquellas asignaturas que fueran más numerosas en el contexto de la oferta que se hacía de los cursos. El programa era muy optativo, probablemente había más de cien asignaturas, de modo que ibas eligiendo.

Yo hice muchas de antropología física, pero en el último año me incliné por la etnología. Y lo hice por una razón: porque en aquel momento llegué a la conclusión de que la idea de ser antropólogo indigenista no entraba dentro de lo que pensábamos que tenía que ser la antropología, teniendo en cuenta que no se contemplaban las culturas urbanas y las civilizaciones modernas. Yo en aquel momento estaba convencido de que la antropología no empezaba allí donde terminaba el asfalto. Es decir, que la antropología debía incluir también a las sociedades modernas.

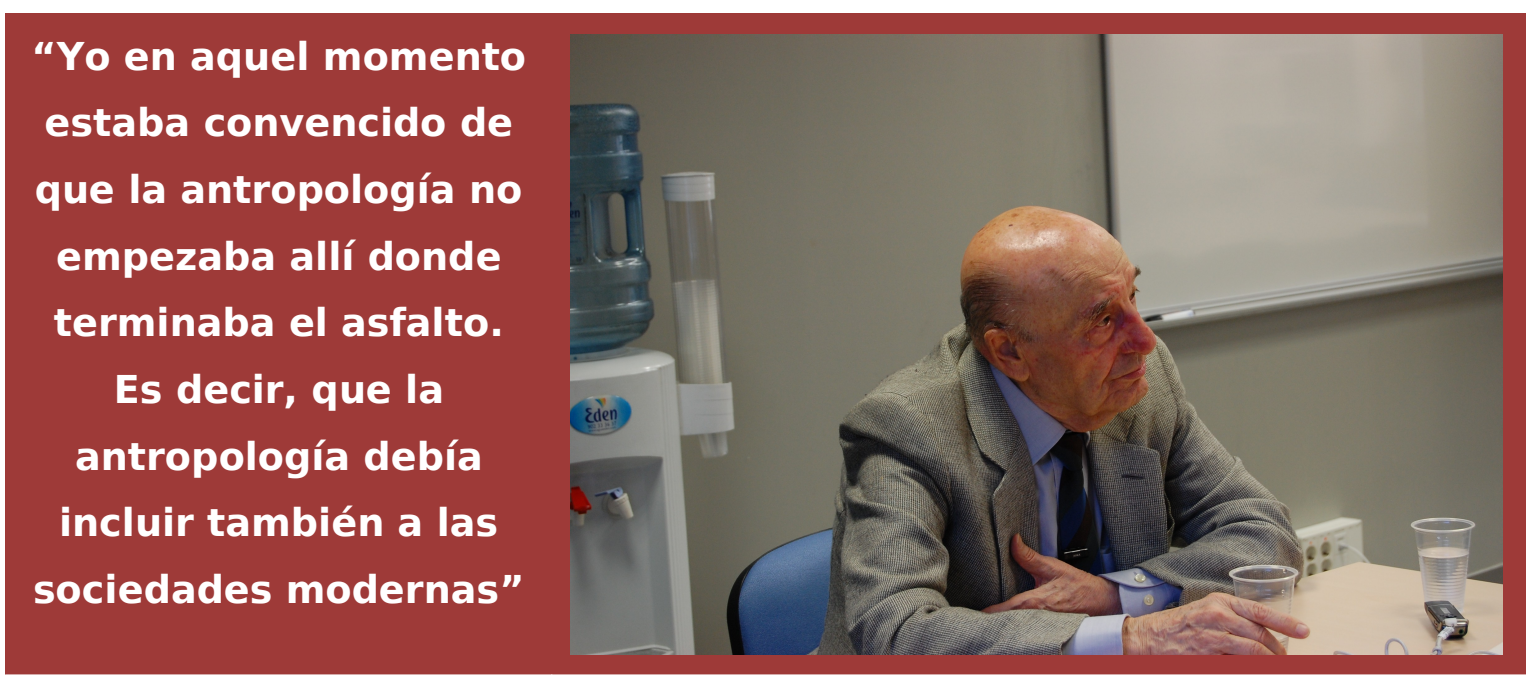

De este modo se nos planteaban problemas muy importantes. Como es el hecho de hasta qué punto esta homogeneidad etnográfica que estábamos produciendo era evidentemente conclusiva. Es decir, si realmente era satisfactorio trabajar sociedades complejas y, dentro de estas, las identidades culturales que se daban. Discutíamos mucho sobre estas cuestiones. Éramos una generación discutidora, pues todo lo encontrábamos mal, incompleto... Y los maestros lo pasaban muy mal con nosotros porque había una concepción abierta de la relación alumno - maestro. Teníamos profesores muy abiertos que no te castigaban porque los criticaras, sino que te premiaban, porque ellos se apuntaban al debate e iban mejorando también. 


\section{perifèria}

Número 14, abril 2011

www.periferia.name

Yo creo que era una escuela única en aquel momento, porque habitualmente el profesor siempre piensa que posee la verdad absoluta y que difícilmente se puede equivocar, porque se basa en los autores más importantes. Pero no es así, porque los autores más importantes, cuando pasan los años, resulta que se postran y dejan de existir.

P: Precisamente, aprovechando que está hablando sobre ello, le queríamos preguntar, ¿cuáles fueron sus principales referentes teóricos cuando empezó a estudiar? Y si a lo largo de todos estos años han ido desapareciendo, como usted ha dicho, y han ido surgiendo de nuevos... ¿Podría profundizar un poco en este tema?

C.E.: Por lo que se refiere a mi ubicación dentro de este contexto, yo pienso que mi primera reorientación se dio en función de una propuesta que me hicieron. En el año 1953 me invitaron a ser profesor de la misma ENAH. Yo aún no había terminado los estudios y un día me llamó el director de la Escuela y me dijo: “Claudio, queremos que usted ya no curse estudios aquí sino que en su lugar imparta asignaturas". Y esto coincidió con que en el Instituto Indigenista de México, su subdirector en aquel momento, Gonzalo Aguirre Beltrán, me propuso que me hiciera cargo de un departamento que ellos tenían en cada área indigenista. Ellos hicieron los Ilamados "Centros Coordinadores Indigenistas", que ordenaban toda actuación de la antropología entre los indígenas.

Él y el director me dijeron que tendría que dejar un poco el estudio de la antropología y que me fuera allí. Yo finalmente no acepté porque el sueldo no me convenció. Yo tenía tres hijos en aquel momento y el sueldo que me daban era sueldo para un soltero, pero no para un casado. Y pensé dónde estudiarían los tres niños, si se harían indígenas... Me planteé problemas de este tipo, problemas de paternidad. Y le dije que no. Pero coincidió esta oferta con el hecho que un día me dijo un compañero mío que había programada en la facultad de filosofía la conferencia de un psiquiatra que hablaría sobre la dicotomía Apolínea - Dionisíaca. Esta es una dicotomía que había planteado Nietzsche en El origen de la tragedia, la cual había sido utilizada por una gran antropóloga norteamericana, Ruth Benedict, para trabajar con los Indios Pueblo, los indios de la Columbia Británica y algunos del Pacífico. ${ }^{6}$

\footnotetext{
${ }^{6}$ Ver Ruth Benedict, Patterns of Culture, 1934.
} 


\section{perifèria}

Número 14, abril 2011

www.periferia.name

Yo estaba trabajando mucho en esta línea en aquel momento, me orientaba hacia la psicología dentro de la antropología. Me parecía muy superior la psicología a la sociología. A mí me parecía que la sociología era un pensamiento de tendencia única por parte de los que la escriben y que las encuestas de los sociólogos las relativizaban todas. Cuando a nosotros nos llegaba una encuesta de los sociólogos nos ausentábamos y pontificábamos que aquello no tenía ningún sentido y que no se aguantaba por ningún sitio, porque nosotros estábamos practicando el método cualitativo, el mismo con el que últimamente los matemáticos se están intentando aproximar a la realidad.

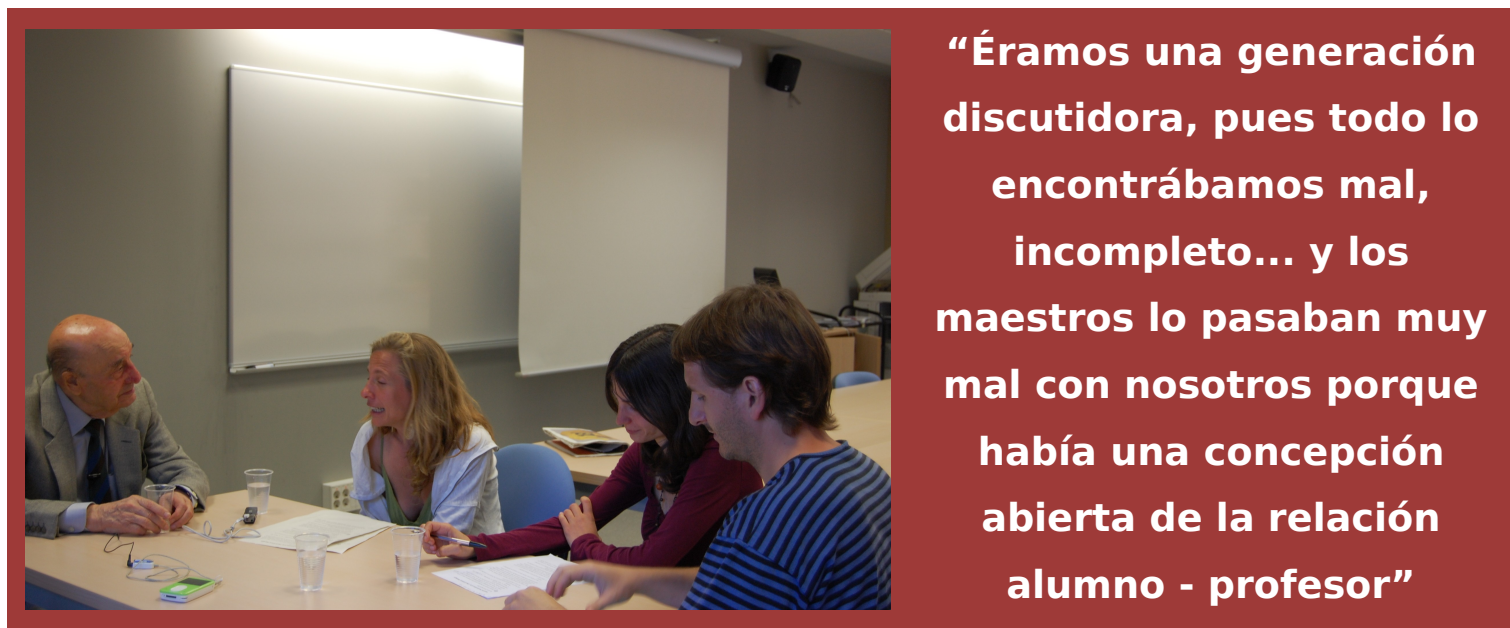

Y entonces, en aquel momento fui a escuchar la conferencia de Raúl González Enríquez, que hablaba sobre esta dicotomía apolínea-dionisíaca. Esta dicotomía era importante porque significaba que el mundo griego tenía un mundo "antiguo" que es la época bárbara (que era el gobierno de la mente por medio de una psicología dionisíaca), y después venía la época "clásica" en la que dominaba el oráculo de Apolo. Y esto creaba dos dimensiones históricas de la cultura diferentes...

Por lo tanto, junto con el estudio que yo realizaba de Ruth Benedict para prepararme el curso que me habían propuesto en la escuela de antropología, también estaba estudiando un autor americano que era Abram Kardiner. Este había publicado también un libro que se llamaba El individuo y la sociedad, editado por Fondo de Cultura Económica. A mí ese estudio de Kardiner me pareció 


\section{perifèria}

Número 14, abril 2011

www.periferia.name

luminoso. En ese momento estuve dentro de la influencia de Abram Kardiner. Su influencia era muy significativa para mi persona porque yo me estaba orientando hacia la psicología dentro de la antropología.

El psiquiatra que estaba dando la conferencia, cuando se acabó abrió un coloquio. Y entonces intervine. Le dije que me parecía que colocar la dicotomía en el mundo pre-hispano (que el mundo pre-hispano estuviera elaborando dos categorías internas, culturales, que eran lo dionisíaco y lo apolíneo) no acababa de encajar dentro de lo que nosotros estudiábamos del mundo pre-hispano.

Raúl González pensaba que los mayas eran dionisíacos y que los náhuatl eran apolíneos. Y presentaba como muestra la arquitectura y, sobre todo, la escultura. En México hay las esculturas de Tula, donde los rostros son de una gran severidad en las figuras, y eso para él era apolíneo, la proyección apolínea. Y después mirando las esculturas mayas vemos que estas tienen una característica bastante frecuente, que es la "cabecita sonriente"; y esto lo definía como dionisíaco. También hay dicotomía en las fiestas: en una fiesta maya hay una gran expansión del espíritu, la gente entra en las órbitas -digamos- fáusticas. Cosa que no le sucede a la gente del altiplano, a la gente náhuatl; son más severos, tienen más autocontrol. Esta idea la estuve discutiendo con él y, cuando se acabó toda mi intervención y la de otros, me dijo: "Oiga, usted trabaja en antropología. Yo estoy muy interesado en la antropología. Y me ha parecido que quizás podríamos convenir alguna reunión porque estamos creando el Seminario del Psicoanálisis. Este seminario ha invitado al Dr. Erich Fromm para que lo dirija y además nos psicoanalice a todos nosotros, a todos los psiquiatras mexicanos."

\section{P: Precisamente Erich Fromm fue para usted una figura clave, que le introdujo a analizar la antropología desde el psicoanálisis. ¿Nos puede explicar cómo fue este proceso?}

Sí, claro. En ese momento en el estudio del psicoanálisis estaba Clyde Kluckhohn, un famoso antropólogo de Harvard que preconizaba que los antropólogos estaban demasiado subjetivados, cuando en realidad todos estaban convencidos que hacían objetivación. Él decía que los antropólogos de campo eran subjetivos. El hecho de escoger una cultura y no otra ya era una muestra de ello. Publicó un artículo muy interesante en el que decía que todos los antropólogos de campo, empíricos (no los antropólogos filosóficos, puesto que estos pueden pensar como les dé la gana), tenían que tener una experiencia psicoanalítica. $Y$ tenían que ser psicoanalizados 


\section{perifèria}

Número 14, abril 2011

www.periferia.name

porque había algunos que exageraban unos significados en detrimento de otros que eran más importantes desde el punto de vista de la socialización del individuo. Esto me convenció mucho.

Entonces me presentaron a Erich Fromm y me nombraron secretario académico de la Antropología Aplicada al Psicoanálisis. Estuve cinco años siendo psicoanalizado por Fromm y estuve trabajando en el estudio de materiales clínicos, dándoles una comprensión de tipo cultural. Hablaba del contexto cultural en donde se encontraba este paciente $y$, entonces, como no había materiales de antropología, estudié la novela mexicana. La novela mexicana me dio tipologías que no me daban los antropólogos, de manera que me aficioné mucho a ella.

"Kluckhohn decía que los antropólogos de campo son subjetivos; el hecho de escoger una cultura y no otra ya es una muestra de ello"

Conocí a Juan Rulfo, sobre quién realicé una intervención en el congreso de americanistas celebrado en México, siendo invitado para realizar la llamada conferencia magistral sobre el autor. Como por ejemplo, uno de los autores que estuve leyendo por consejo del mismo Erich Fromm fue Dostoievski: Crimen y castigo, Los hermanos Karamazov,... Y como durante mi adolescencia había leído los autores rusos (Tolstoi, Turgénev, Gógol, Dostoievsk), en fin, todos ellos, entonces para mí no era una novedad.

Lo que sí era una novedad era el planteamiento metodológico, la epistemología de la novela. Entonces Raúl González Enríquez, que era muy amigo de Alfonso Caso, un antropólogo-arqueólogo, me pidió que diera un curso de Cultura y Personalidad en la ENAH, de manera que esta fue mi orientación. Di este curso, que se completó con una Historia de la Cultura y con uno de Análisis de la Personalidad. Y desde el año 1953 hasta 1956 estuve dando estos cursos en la ENAH. De hecho figuro en los anuarios de la ENAH como el profesor que inauguró estas líneas de investigación. Y tuve muy buenos alumnos, que también sostuvieron la idea de que era más interesante la psicología que la sociología. De manera que cualquier intento de pensar con Max Weber era substituido por la idea de pensar con Freud. Todos llegamos a la conclusión que Weber no nos servía para el estudio de grupos 
perifèria

Número 14, abril 2011

www.periferia.name

indígenas, dándonos cuenta que por esta vía estábamos perdiendo el tiempo. Entonces me orienté hacia el psicoanálisis.

P: A mediados de los años cincuenta, en plena dictadura franquista, decidió volver a España. Los primeros años los pasó en Madrid donde, entre otras muchas cosas, impartió docencia en la Universidad de Madrid, tomó el relevo de Don Julio Caro Baroja en la dirección del Museo Nacional de Etnología y creó la Escuela de Estudios Antropológicos, que dirigió hasta finales de los años sesenta. ¿Cuáles fueron los motivos que le hicieron volver en pleno franquismo? ¿Conocía cuál era la situación de la antropología en España en esos momentos?

C.E.: En el año 1956 acabé el período mexicano porque el partido que habíamos fundado en México, el PSC (el Partido Socialista Catalán y no el Partido de los Socialistas Catalanes), había establecido un programa inicial por el derecho a la autodeterminación como un factor fundamental dentro de una política catalana. Y como yo era el más jovencito de todos, se decidió que yo era la persona apropiada para volver.

Ellos [el régimen franquista] pensaron que si yo volvía lo hacía, en primer lugar, como profesor y como persona responsable, sin antecedentes policiales. El partido pidió previamente información sobre si la policía de aquí tenía alguna cosa contra mí y resultó que los vecinos decían que yo era un chico magnífico, que nunca había matado a nadie. Y es verdad. Así que pensaron que yo era la persona idónea.

Esto lo explico en un libro que acabo de publicar, hace un par de meses y que se Ilama La influencia de México en el Exilio Español. ${ }^{7}$ Pero en aquel momento había una discrepancia entre las posiciones en el exilio y las posiciones desde el interior del país. Las posiciones del interior eran más plásticas, tenían presente la idea de que el franquismo existía y, que por lo tanto, se tenía que negociar un poco la propia presencia de un socialismo democrático dentro del país. Se tenía que negociar con todos, incluso con lo que mandaban. La postura de los que vivían en el exilio negaba rotundamente toda idea de llegar a contactos o aproximaciones con el régimen. $Y$ no se dieron situaciones que me permitieran volver a Barcelona, porque mi entrada en la Universidad era, en ese momento, imposible.

\footnotetext{
${ }^{7}$ Ver Claudi Esteva Fabregat, La influencia de México en el exilio español. Identidades en retrospectiva, Veracruz, México: Editorial del Gobierno del Estado de Veracruz, 2009.
} 


\section{perifèria}

Número 14, abril 2011

www.periferia.name

Pere Bosch Gimpera, que vivía en México, conocía gente del país, de aquí España, que eran relativamente franquistas y que estaban dispuestos a ayudar a uno que viniera del exilio, como era mi caso. Y Bosch Gimpera, juntamente con Joan Comas, escribieron algunas cartas y realizaron algunas llamadas a Madrid que me permitieron volver. Yo tenía - por decirlo de alguna manera - un buen cartel, de manera que se decidió que volviera por Madrid, aprovechando las oportunidades que se me ofrecían para volver.

Durante mi estancia en Madrid formé la Escuela de Estudios Antropológicos, hacia el año 1965. Tuve contactos muy importantes con gente de la universidad que me apoyaron, convenciéndoles de que la antropología sería lo que iría bien para el futuro académico. Convencí a Ballesteros, que me trató siempre como a un amigo, y entré en el Consejo de Investigaciones Científicas como colaborador; sin cobrar, evidentemente. Yo hacía ahí las recensiones críticas de la Revista de Indias y me dieron toda la parte de antropología de la América Hispánica. También realizaba encuestas con la convicción de que no servían para nada, pero de todas formas... hacía encuestas porque me las pagaba la Cámara de Comercio.

Entonces participé en el Congreso Internacional de Americanistas que se celebró en 1964 en Barcelona, en Madrid y en Sevilla, en donde conocí a un montón de gente, pero especialmente al director del Instituto Fernández de Oviedo del CSIC. Y también es cuando conocí a Manuel Ballesteros y a Lluís Pericot, que era catedrático de prehistoria aquí en la Universidad de Barcelona. Le dijeron al Director General de Bellas Artes que yo sería el mejor candidato para dirigir el Museo Nacional de Etnología de Madrid.

\section{P: Explíquenos cuál fue su experiencia enfrente del Museo Nacional de Etnología y las dificultades que encontró en los primeros días.}

C.E.: Todo empezó cuando Lluís Pericot me dijo: “Oiga, Esteva, ahora en el Museo está [Julio] Caro Baroja, pero no hace nada aquí y usted debería aceptar ser el director. Hemos pensado que usted sería la persona idónea." Yo ya trataba con Caro Baroja ahí y se lo comenté. Él me contestó: "Yo encantado de la vida de que usted se haga cargo del Museo Etnológico. Yo, francamente, no voy por ahí; solo voy a firmar la nómina y nada más" [risas].

El museo se encontraba en un estado lamentable: no tenía luz cuando yo entré. La compañía eléctrica había suspendido el suministro de electricidad porque no 


\section{perifèria}

Número 14, abril 2011

www.periferia.name

pagaban. Y esto dependía del ministerio; así pues, el ministerio no pagaba. Y Caro Baroja, francamente, no se ocupó de ello. Yo le dije al principio que no me interesaba, porque no tenía sueldo, y me dijeron: “No, pero se le puede dar una gratificación por el trabajo, y en esta gratificación se le puede dar una pequeña cantidad". Acepté y, si no me equivoco, la gratificación eran dos mil pesetas mensuales, para cubrir un poco las apariencias.

Cuando me hice cargo del Museo Nacional de Etnología llegué a la conclusión que se podría intentar incluir los cursos de antropología que no existen aquí. Pericot me dijo: “Esto podrá hacerlo dentro del museo; en la universidad no, no, no... En la universidad no." Y entonces le dije: "¿Pero habrá alguien a quien no le parezca bien que lo haga dentro del Museo de Etnología?” y me contestó: “iAh, no! Usted será el director y, por lo tanto, podrá hacer cursos de antropología ahí". Entonces acepté.

Recuerdo que el primer día que entré, cuando me presentaron los bedeles de los ordenanzas, el museo estaba abierto pero había velas encendidas. Me presentaron a María, que era la que iba uniformada y daba los boletos para entrar. "¿Y lo de las veladoras estas?", le pregunté. “No, es que la compañía eléctrica ha suspendido la electricidad. Es que no la pagan". Telefoneé a Caro Baroja: "Oiga, que me han dicho que no pagamos la electricidad...". "Bueno, hay y habrá peores cosas que verá usted [risas]. De momento me parece que si hace usted un inventario va a tener sorpresas". E hice el inventario.

“El museo estaba en un estado lamentable: no tenía ni luz cuando llegué.

Cuando se necesitaba dinero

se vendían objetos del

museo"

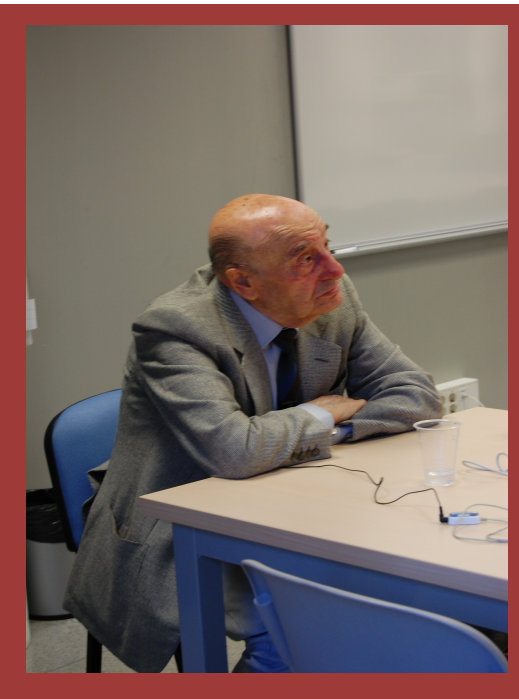




\section{perifèria}

Número 14, abril 2011

www.periferia.name

Al cabo de unos días fui a ver al director de Bellas Artes, Gratiniano Nieto, y le dije que teníamos el problema de la suspensión de la luz y de la desaparición de las piezas. Le dije que me estaba ocupando de todo y que había descubierto que en la Cuesta de Moyano había colecciones de antropología alemana que habían sido vendidas por el director del museo, anterior a Caro Baroja (porque este, aunque no hizo nada para recuperarlas, tampoco era persona para hacer una cosa de este tipo. Lo había hecho el anterior director y el anterior a ese). Cuando se necesitaba dinero se vendían objetos del museo. Le dije a Nieto que publicaría el tema de la desaparición de las piezas y me suplicó que no lo hiciera, que encontraría la manera de resolverlo. Lo que sí que salió publicado en el diario $A B C$, no obstante, fue la noticia de que en el Museo Nacional de Etnología habían suprimido el servicio de electricidad y de esta manera lo supo todo el mundo. Fue un desastre. Por otro lado, al preguntarle a María sobre la recaudación me dijo que siempre se la daba al señor Pérez de Barradas. María me explicó que cuando acababa el día le entregaba la recaudación, aunque era muy poca, porque eran diez o doce entradas. Cuando el director recibía la cantidad le decía: “María, vete al bar y que te den unas cervezas y unas olivas, y el resto te lo quedas tú". Le daba cuatro pesetas. Este era el espectáculo. Entonces le pregunté al director general que cómo lo teníamos que hacer para renovar el museo. Nieto me dijo: "Pues no hay presupuesto todavía pero voy a ver si le consigo para el próximo año algo".

Pasado un tiempo me presentaron a Fraga Iribarne, que en aquellos momentos era Ministro de Información y Turismo. Me parece que era catedrático de historia política o algo así. Fraga me dijo: "¿Usted es el actual director del Museo Nacional? Usted viene de México, ¿verdad?". Yo le dije: “Sí, sí. Vengo de México". Y dice: “Bueno, bueno, bueno, bueno. ¿Y cómo tiene usted el Museo?" Y le dije: “Pues mire, lo tengo a oscuras [risas] y tengo ahí unas veladoras encendidas, y estoy haciendo el inventario" (en el inventario faltaban mil seiscientos sesenta y pico objetos del museo, que son piezas de etnología). También le comenté que no disponía de mobiliario y él me dijo que lo pidiera, aunque ya lo había hecho al director general y me lo había denegado por falta de presupuesto. Fraga me sugirió que no había planteado bien el tema: "Aquí tiene usted que hacer una cosa. Pídalo por adelantado a un presupuesto que todavía no le han dado, y entonces se verán obligados a pagar la deuda" [risas]. Entonces me fui a una mobiliaria de la calle Serrano, que es una calle de la aristocracia madrileña y me presenté como el nuevo director del museo y les dije que me gustaría equiparlo. $Y$ entonces me lo renovaron 


\section{perifèria}

Número 14, abril 2011

www.periferia.name

todo. Hice una sala de conferencias, dos seminarios, hice las aulas... Cuando se enteró el director general saltó de la silla [risas]: “¿iQuién le autorizó a usted?!”. Dije: "Nadie, señor. Se trata de un consejo con fundamento [risas]. Ya puede usted decidir que me voy".

P: Después de haber superado estos problemas al frente del Museo se aventuró con otro proyecto que tendría mucha relevancia. Explíquenos cuál fue el proceso de creación de la Escuela de Estudios Antropológicos.

C.E.: En 1965 planteé al Instituto de Cultura Hispana hacer una escuela de antropología que estuviera dirigida a la formación de diez becarios de Hispanoamérica y diez becarios españoles. Y me dijeron: "Háganos el proyecto y veremos qué decidimos". Entonces hice el proyecto, me lo aprobaron y se hizo la Escuela de Estudios Antropológicos. Conté con el apoyo y con los ánimos de mucha gente de la academia.

Entonces contraté a gente de fuera, gente de América, porque me encontré que no había gente para dar la antropología tal y como yo la pensaba. Pensé la Escuela tal y como se impartía en los Estados Unidos, que era de la misma manera que se hacía en México. Es decir, según las cuatro ramas: la etnología, la antropología física, la arqueología y la lingüística. Creo que los que salieron de la Escuela también han jugado su papel dentro de la antropología española, porque prolongaron un poquito esta influencia sobre sus profesores.

P: Su llegada a la Universidad de Barcelona marcó un paso muy importante en la institucionalización académica de la antropología. ¿Nos puede explicar cómo fueron esos primeros momentos?

C.E.: El año 1968 me llegaron rumores de que iba a cambiar el gobierno y me dije: "Si cambia el gobierno, cambia todo". Era un gobierno franquista. Los cambios serían para cambiar todo el sistema. Entonces se convocó la Agregaduría de Etnología de la Universidad de Barcelona. Pericot me avisó y me dijo: “Mire, yo tengo que decirle que nosotros tenemos un candidato, formado por nosotros", que era August Panyella, director del Museu Etnològic de Montjuic (en Barcelona). August Panyella era un buen amigo mío, vino a Madrid y me dijo: “Claudi, ¿qué piensas hacer? Yo no he hecho el doctorado, pero de todas maneras el Dr. Pericot y el Dr. Maluquer piensan que si hago el doctorado ya tendré suficiente. Pero yo ya estoy bien en el museo y me gustaría mucho que vinieras a Barcelona. Ahora, si se 


\section{perifèria}

Número 14, abril 2011

www.periferia.name

presenta algún otro yo iré, pero si te presentas tú, no". E hice la oposición. Se presentaron trece personas de todo tipo, me parece. Y gané la oposición. Cuando llegué a la Universidad de Barcelona entré en el Departamento de Prehistoria, porque la asignatura era de etnología y en aquellos momentos la etnología estaba dentro del Departamento de Prehistoria.

Entonces estuve dos años dando una "Etnología de los Pueblos Primitivos", teniendo en cuenta el hecho que estaba colaborando en un departamento de prehistoria. Pero la idea era independizarme y crear un departamento propio.

P: Cuando le dieron la primera cátedra de antropología, usted defendió una antropología cultural, evitando que constara el nombre de social o de etnología. ¿Nos podría decir cuáles fueron los motivos y, de nuevo, las dificultades que encontró para tirar adelante con su proyecto?

C.E.: Pues mira, un día me reuní con Fabià Estapé y con Joan Maluquer y me dijeron: "Escucha Claudi, acabamos de recibir diecisiete o dieciocho cátedras del ministerio y hemos pensado en ti. Pero tenemos que darles un título". Maluquer dijo: “¿Le ponemos el título de Etnología?". Yo dije que no, porque con una etnología no me defiendo, porque todo el compromiso intelectual que yo tengo con una etnología aquí sería hacia los pueblos primitivos, enseñando una etnología como si fuera el estudio de los pueblos primitivos. Y esto yo no lo pienso. Les dije que yo más bien me inclinaba por una cátedra: “Mire, yo mantendría la agregaduría de Etnología y mi idea es ponerle "Antropología Cultural", porque la antropología cultural la engloba, la incorpora, tiene dentro la etnología. Pero además, estoy pensando en la lingüística y estoy pensando en esto vuestro, la arqueología y la prehistoria; y esto también podría estar ahí. Entonces daríamos la "Antropología Cultural" sobre la base de que es la teoría de la cultura, la que yo quiero enseñar. $Y$ esta teoría de la cultura servirá para estas cuatro ramas".

En aquellos momentos yo quería evitar ponerle el nombre de antropología social porque si íbamos por ahí, los tribunales serían de sociología. Y si poníamos un tribunal de sociología vendría al tribunal un personaje de la sociología o algún otro y no habría una antropología tal y como yo la planteaba. No quería pasar por un tribunal de sociología, porque ya había pasado por uno una vez y el presidente era Fraga Iribarne y votaron por Salustiano Del Campo. Yo me presenté porque era en Barcelona y también había dado sociología, por tanto estaba en condiciones de dar una sociología culturalista. Pero a nosotros, en la facultad, no nos convenía el 


\section{perifèria}

Número 14, abril 2011

www.periferia.name

nombre social porque recibiríamos por todos lados, sobre todo de los sociólogos. Por este motivo propuse que la cátedra tuviera el nombre de Antropología Cultural. Le dije a Estapé: “Mira, ya se lo he explicado a Maluquer porqué cultural: porque tenemos que evitar el intrusismo dentro de la antropología cultural. La prehistoria es una parte de la antropología", le dije, "de manera que ponle cultural".

Entonces me pareció adecuado ir a hablar con Alcobé Noguer, que era de antropología física y que fue rector de la Universidad de Barcelona. Era antropólogo físico, biólogo y médico... Un tipo muy inteligente; muy acostumbrado a mandar y a decidir, pero muy inteligente. Cuando hablé con él le dije: “Mire, tengo la idea de la antropología en base a las cuatro ramas mencionadas, ya que es lo que estudié". "Ya, esto es americano. La antropología es y tiene que ser una antropología física", me dijo. Le respondí que no, que "la antropología es el estudio del hombre; no el estudio del hombre físico, sino el estudio del físico y del cultural". "No, ni pensarlo, ni pensarlo". Entonces no hubo la oportunidad de juntar el departamento de antropología física y el departamento de antropología cultural. No hubo posibilidades.

Entonces también estaba Marsà, que empezaba a hacer lingüística y le dije a Badia (Badia y Marsà no se llevaban muy bien entre ellos): "Escucha, convendría que ahora que hay la opcionalidad [en las asignaturas] metiésemos una teoría de la lingüística". Es decir, el enfoque del estudio de la palabra, no de la escritura, que es lo que hacen los filólogos. "Tendríamos que considerar los lingüistas y que hiciesen trabajo de campo, y que hablasen de arqueología y de una serie de cosas propias de los lingüistas". Y me dijo Badia: "Mira, aquí te encontrarás muchos inconvenientes, porque hay muchos intereses dados. Habla con Bastardas", que entonces era filólogo. Con Bastardas estábamos haciendo el plan Maluquer, junto con Marsà, Cerezo (que había venido de Jaén y después se fue a Granada) y yo. Estos éramos los que hicimos el plan Maluquer. Los cuatro. Le llamamos Maluquer porque este nos apoyaba, lo aprobaba y le dábamos una opcionalidad nueva.

La idea que tuve después, una vez conseguí la Cátedra de Antropología Cultural, fue que los alumnos que estudiaban en el departamento de antropología cultural hiciesen asignaturas optativas de lingüística. Convencí a Marsà para que hiciese un artículo para Ethnica, la revista que creé en aquel momento, para insistir en el tema de la importancia de la lingüística en la antropología. Marsà fue muy favorable a 


\section{perifèria}

Número 14, abril 2011

www.periferia.name

esta idea, mientras que Badia no lo era tanto, porque tenía problemas de tipo, no diré jurídico, pero sí de orientación de la filología. Entonces Marsà defendió la opcionalidad y dio lingüística.

También planteamos que los alumnos que cursaban Antropología Cultural estudiasen materias que se daban dentro del departamento de Antropología Física. También pedí a un profesor de matemáticas que nos preparase un curso de matemática cualitativa destinada a los antropólogos culturales. Todo esto se consiguió. Pero los alumnos estaban descontentos porque se sentían arrinconados e incómodos en la facultad de biológicas, de manera que les dije que era optativo. De esta forma, esta opción terminó por no utilizarse. Que yo recuerde estudiaron esta rama Dolors Comas, por ejemplo, que me hizo caso y fue a hacer un curso de antropología física; mi hija también... En fin, fueron algunos. Pero se encontraron con la hostilidad - digamos académica -, del ambiente, con lo que se fracturó la idea de seguir en esta línea.

Conseguimos, pues, que la Antropología Cultural fuera la dominante. En ese momento, pero, el problema era quien impartía este tipo de docencia. El primer año di yo el curso de Antropología Cultural, pero el segundo año decidimos que la Antropología Cultural figurase ya en el primer año, y que este fuera el año de las troncalidades. Entonces las troncales eran Historia, Geografía Humana, Geografía Física, Historia Moderna, Historia Contemporánea, Filosofía... La cuestión era la troncalidad. En la alternativa que se daba entre Filosofía o Antropología Cultural, ganó esta en la Junta de Facultad. El catedrático Emilio Lledó se enfadó mucho, pero yo lo disputé porque de esta manera daba la oportunidad de ofrecer la posibilidad a los que estaban entrando como "señores", a aquellos que ya tenían título de doctores, del grupo que yo había formado. Estaba Joan Frigolé, Jesús Contreras, Ignasi Terradas, María Jesús Buxó, Juanjo Pujadas, Dolors Comas, Josep Maria Comellas, Joan Prat, Oriol Romaní. Yo no les podía dar sitio a todos, pero cada uno hacía tres Antropologías Culturales, de modo que teníamos, en la primera etapa, convergiendo con este primer curso troncal, cinco plazas para ellos.

\section{P: Doctor Esteva, explíquenos cómo concibe usted la antropología social y qué reflexiones ha hecho sobre ésta rama de la disciplina.}

C.E.: Bueno, esta es una deriva muy interesante. Di antropología social en México, y cuando llegué aquí, en España, ya había dado en México antropología social en la 


\section{perifèria}

Número 14, abril 2011

www.periferia.name

Facultad de Medicina, en la sección de Psiquiatría, debido a mi contacto con Fromm y con los psiquiatras. Entonces yo pensaba la antropología social como una variable de la antropología, es decir, siempre la he pensado como una especialidad. Pero el entrenamiento del alumno debería ser el que me he referido anteriormente, a la manera americana. Un entrenamiento en el que la gente se entera de lo que es la historia, lo que es la lingüística, lo que es la arqueología y de lo que es la antropología física. Entonces incorporé la idea de la antropología social como una quinta rama, y más tarde he incorporado - estando en México - la idea de la etnohistoria.

Entonces tenemos la antropología que se hace en la UNAM y la ENAH, que sigue siendo la misma que había antes, la que estudié yo, pero con la incorporación de la antropología social y de la etnohistoria. De esta manera, el componente histórico y el sociológico de alguna manera complementan el entrenamiento que se ha recibido en esta idea de antropología. El hecho es que la antropología social, yo ya lo he denunciado, está renunciando mucho a la etnografía. Es decir, hay poca etnografía y esto es lo más importante de la antropología, ya que es el material didáctico del antropólogo. Es el resultado de las monografías de campo, que también se pueden hacer en términos de etnohistoria. Y por lo tanto, mirando los trabajos que se hacen, se aproximan más hacia la sociología pero sin ser sociología.

\section{P: ¿Qué opina de la deriva de la antropología europea, en un momento determinado de la historia, hacia la antropología social, dejando de lado el estudio de las mismas sociedades postindustriales?}

C.E.: Hoy en día se puede notar que en Europa la antropología social ha tomado los materiales del folklore, apropiándose de los campos del folklore, de modo que están todos distribuidos: la fiesta, los toros... Todo ello está tambaleándose. iDebemos tener cuidado con eso! Debemos estar alerta de no aproximarnos a la idea de que la antropología social es una rama de la sociología, como dijo Radcliffe-Brown. Este dijo que es una rama de la sociología comparada. Cuidado. Y una rama de la sociología comparada, entra dentro de la perspectiva de Durkheim.

Radcliffe-Brown defendió la idea de la antropología social en un momento clave en la historia de Inglaterra, y es que estaba perdiendo su imperio colonial. Y este imperio colonial ya no daba tantas distribuciones de dinero a los antropólogos británicos para que hicieran la etnografía de las tribus, porque básicamente esta antropología social británica trabajaba con tribus. No se les ocurrió que también la 


\section{perifèria}

Número 14, abril 2011

www.periferia.name

sociedad contemporánea, la urbana, la civilizada, también tiene problemas de campo. Lo único que tienen que hacer es un poco el esfuerzo de acostumbrarse a trabajar dentro de la sociedad urbana, de la sociedad global, porque nos pertenece también; no diré por instinto, pero sí por convicción.

En términos cualitativos las etnografías urbanas son más difíciles que aquellas etnografías que encontramos homogéneas o uniformes, cuando vamos a una tribu que no tienen diversidad interna. Pero Radcliffe-Brown, en ese momento, se encontró que volvía a Inglaterra y los etnólogos no lo querían, porque los etnólogos de Inglaterra estaban trabajando en la museografía.

Radcliffe-Brown y Rivers fueron los precursores de la antropología social, inclinándose hacia la sociología sin ser sociólogos. Es decir, eran antropólogos pero tuvieron que inventarse un nombre para legitimar el cambio de etnología hacia antropología. Y así es como inventaron el de antropología social, porque este nombre no les causaba problemas de legitimidad ante los etnólogos. De modo que yo creo que este antecedente es muy importante.

También hay que tener en cuenta el trabajo de Malinowski, contemporáneo a Radcliffe-Brown, que trabajó en las Trobriand durante cuatro años. Trabajó empujado por el contexto histórico que vivió. Como polaco de origen le habían dicho que le tenían que encerrar en un campo de concentración. Pero los antropólogos británicos se negaron y dijeron que no era un enemigo: "Él es polaco de origen, ha estudiado etnología en Alemania y en Inglaterra, donde lo ha hecho por convicción ideológica. Ya que no le interesa la Alemania con Hitler, con los nazis, con todo esto". Y entonces los antropólogos británicos encontraron la solución de decirle al gobierno que fuera a hacer trabajo de campo en una de las islas que tenían en Oceanía, y como no sabía nadar, seguro que de allí no se movería. Pensaron que allí se encontraría bien. Después no se encontró bien porque añoraba la novia. Si leen su obra verán que añoraba la novia que había dejado en Inglaterra.

Radcliffe-Brown y Evans-Pritchard se lo quitaron de encima porque la idea de Malinowski era una idea etnológica por sus antecedentes. Pensaron que "aquí Malinowski no nos irá bien", por lo que le dieron eso. Malinowski fue a Estados Unidos y estuvo en México, donde hizo un estudio de un mercado dejando una huella fabulosa. 


\section{perifèria}

Número 14, abril 2011

www.periferia.name

P: Volviendo a Catalunya, nos gustaría que nos explicara cómo vivió usted el hecho de que en las universidades catalanas, concretamente en la de Barcelona, no se acabara siguiendo el modelo que usted planteó. De hecho, es curioso que la antropología que se enseña reciba el nombre de cultural pero que, en cuanto a los contenidos y a la metodología, ha tendido hacia la rama social.

C.E.: Pues mira, yo lo viví como una manera cómoda de afrontar el problema de la antropología, del concepto de antropología. Como una manera cómoda de no ir en contra de éste, del otro; vamos por aquí y por aquí, todos nos colocaremos. ¿Por qué? En primer lugar, porque las circunstancias estaban favoreciendo más la creación de una antropología social que una antropología cultural.

Pienso que debe producirse un consenso para evitar peleas que luego perjudican mucho la percepción que puede tener un ministerio. Yo creo que han mantenido la idea social por encima de la cultural. ¿Por qué? Bueno, en primer lugar porque el ministerio está en Madrid. Y Salustiano del Campo y Carmelo Lisón también. Lisón se hace llamar antropólogo social. Cuando él estudió en Galicia, dice que hizo una antropología cultural de Galicia. ¿Y por qué lo hizo? Porque estaba Claudi Esteva. Porque estaba Esteva dijo: "Este tal vez me perjudicará porque lo tendré en un tribunal". Son estrategias de la gente. Y Lisón y Salustiano del Campo son muy amigos y están dentro del mismo departamento de sociológicas. Entonces toda la gente que tienen allí está formada en sociología y que les des allí una antropología cultural, no la ven. Lo que ven es una antropología social. Y entonces Claudi Esteva se ha ido del país y Lisón ha quedado como el dueño absoluto del problema. Y a Lisón, pues, le llaman al ministerio y le preguntan: "¿Dónde ponemos la antropología?". Salustiano del Campo lo apoya y aunque tiene enemigos, son enemigos dentro de la sociología pero no enemigos dentro de la antropología. Porque uno de los enemigos posibles dentro de la antropología sería, posiblemente, Claudi Esteva. Y posiblemente Claudi Esteva, si hubiera ido a negociar con el ministerio, no se hubiera dado esto; posiblemente. ¿Por qué? Pues porque yo hubiera operado de una manera diferente. Pero claro, la gente, la identidad [de la antropología], siempre es un problema negociado. 


\section{perifèria}

Número 14, abril 2011

www.periferia.name

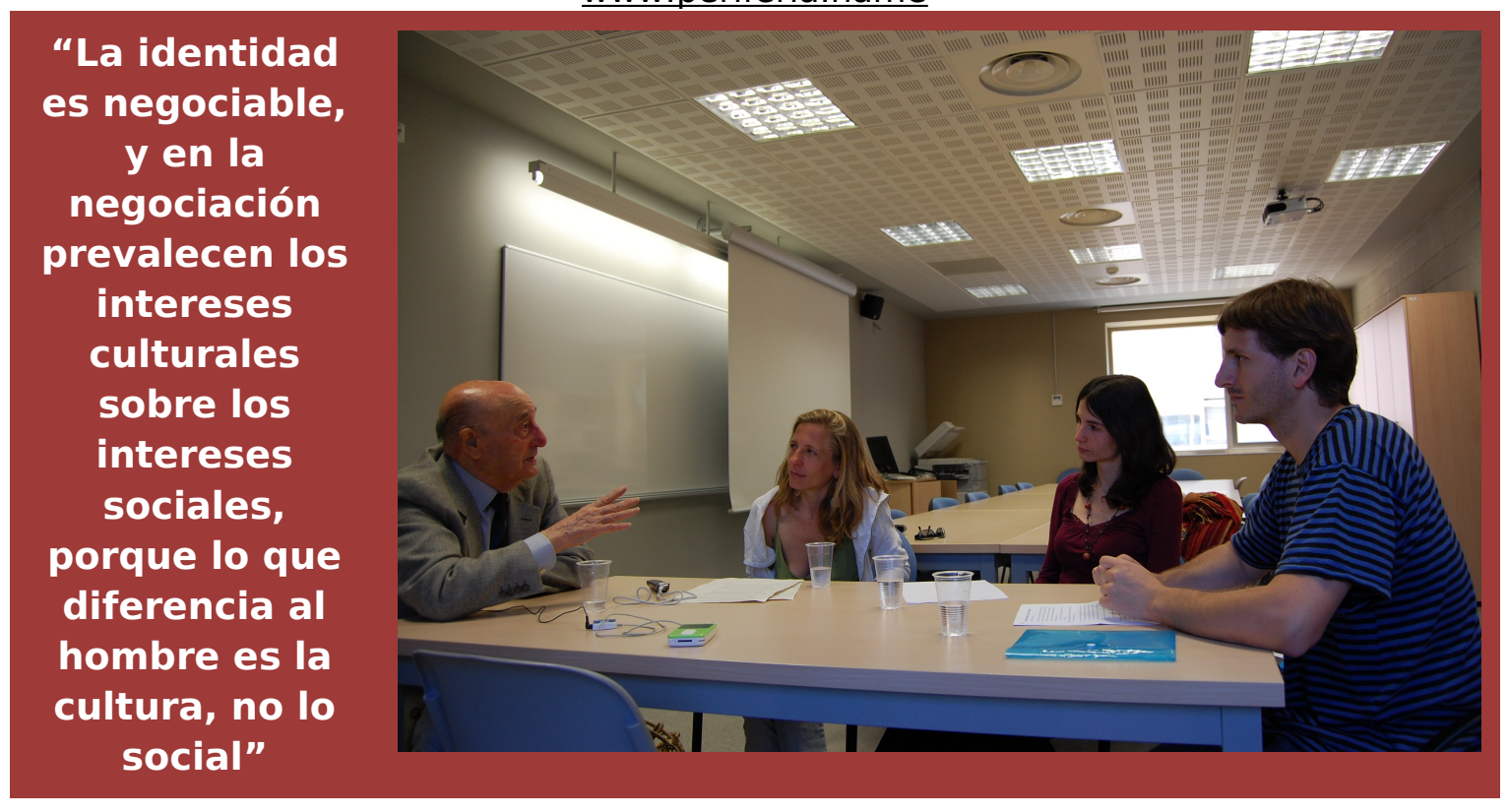

La identidad se tiene que negociar. Y en la negociación hubieran prevalecido los intereses culturales sobre los intereses sociales, porque lo que diferencia al hombre es la cultura, pero no lo social. Todos los animales son sociales, ya desde el punto de vista del origen conceptual. Yo veo mucho los vídeos de leones, de felinos, todos son sociales... Esto también lo tenemos nosotros; todo esto, con categorías diferentes, con una dialéctica específica.

Mire, cuando Lisón vino a Madrid, yo había fundado la Escuela de Estudios Antropológicos. Él me vino a ver y me dijo: "Bueno, quería conocerte. Venía para ver si me dabas un lugar por aquí..." Y le dije:"Con mucho gusto". Le di las dos asignaturas que yo impartía, se las di a él y me inventé otras para poderlo colocar allí.

Presenté un proyecto al ministerio cuando vine aquí en Barcelona, un proyecto en el que me planteaba el dilema de qué harán los chicos y chicas que salgan de una carrera de antropología cultural. Se puede hacer una antropología aplicada. Como hice yo cuando fui África y cuando trabajé en México: una antropología aplicada. Pero hay que convencer a la gente de que la antropología aplicada tiene formas, medios, para resolver problemas de la industria y de la agricultura... Y aquí no creo que nadie de ellos esté preparado para ello. Todo ello existía en la idea, pero se necesita tiempo para entrenar un grupo, se necesita tiempo. 
perifèria

Número 14, abril 2011

www.periferia.name

P: Hay tantas cosas que preguntarle... Otro tema del que quisiéramos hablar es de sus discípulos. Usted ha sido maestro de muchos estudiantes que ahora son profesores nuestros. $Y$ bien, nos gustaría que nos hablara un poco de los discípulos que ha tenido en México, en Madrid y en Barcelona; los que quizás han seguido más su línea...

C.E.: Bueno, yo creo que de mi línea, digamos la que realicé yo aquí, la persona más afín fue María Jesús Buxó. Ella era la más afín porque también estudió en Estados Unidos y estudió antropología dentro de esta línea. Y por lo tanto, yo la preferí a la hora de priorizar una incorporación a la antropología cultural. Ahora, yo creo que el departamento ha tenido y tiene magníficos intelectuales de la antropología. Por ejemplo, Ignasi Terradas es una persona de una capacidad intelectual extraordinaria, es muy inteligente. Estudió conmigo y luego se fue a Inglaterra, a Manchester; yo creo que es una persona de una gran categoría intelectual. También Joan Bestard es otro gran antropólogo, es una gran persona, muy inteligente, muy preparado y yo le tengo mucha confianza. Después también está Joan Frigolé, un muchacho muy inteligente, Jesús Contreras, Xavier Roigé y otros. Estos han estudiado conmigo.

Permítanme que les diga que todo el grupo que está dentro de esta facultad de la Universidad de Barcelona es un grupo magnífico. Yo creo que como grupo es el mejor de España. Lo digo con toda sinceridad. Este grupo hace libros y sabe defender sus tesis. Y va por el mundo y les llaman para ir a Portugal, a Francia, a Italia, a Alemania, a Polonia. Es un grupo de proyección internacional. Van a México constantemente y en la UNAM de México les tienen un gran respeto. Tienen un gran respeto por la gente que viene de Barcelona. Y esta es la realidad. Van al CIESAS [Centro de Investigaciones y Estudios Superiores en Antropología Social de México] y dan conferencias y hacen contactos en materias de antropología social. Y lo hacen muy bien. Una vez, cuando fui a la UNAM, un compañero mío me dijo: "Oye estamos trabajando con Jesús Contreras, un tipo inteligente...". Quiero decir, eso te lo dicen los demás. Estoy hablando con toda la sinceridad. Son seis catedráticos, no es por casualidad. iSeis catedráticos!

En Madrid está Manuel Gutiérrez Estévez. Fue el alumno más brillante en la Escuela de Estudios Antropológicos. Es de una capacidad combinatoria que poca 
perifèria

Número 14, abril 2011

www.periferia.name

gente la tiene. También tuve Rogelio Rubio que está en la UNED, un poco libre pensador, se fue a la India donde tomó mucha experiencia de antropología. Ha hecho publicaciones sobre la India.

En la antropología había lo que se llamaba el ritual de pasaje en el trabajo de campo. Es el ritual que prueba la capacidad del antropólogo para hacer antropología y que incluía también la obligación de que fuera en una cultura diferente. Rogelio hizo etnografía de una cultura diferente. $Y$ después Manuel Gutiérrez estuvo trabajando con la idea de Castaneda, ${ }^{8}$ pero está haciendo un trabajo mejor que el de Castaneda, porque con Castaneda se tiene la duda que realmente hubiera visto todo lo que dice. Es muy diferente. Hay dos antropólogos americanos que cuando estaba yo en Vancouver me dijeron: "Mira Claudio, este Castaneda es un intruso de un atrevimiento que no sabemos cómo impedir que vaya intoxicando a toda la juventud que estudia antropología. Nos está intoxicando, todo es mentira". Él no ha estado con Don Juan. Yo, que conste que no conozco a Castaneda pero sí he leído lo que ha hecho. Aquello no se aguanta por ninguna parte. No tiene ninguna lógica interna, no es coherente con la cultura de la que habla. Pero es un libro que le ha hecho millonario, porque todo el mundo lo ha leído. Mientras algunos se han entusiasmado y han hecho imaginaciones...

P: Si nos permite, y ya para ir terminando la entrevista, quisiéramos que con su perspectiva privilegiada de 70 años de antropólogo, nos diera algún consejo sobre métodos, paradigmas, etc. Usted, con su trayectoria, ha conocido escuelas de todo tipo. Nosotros, como estudiantes o como futuros antropólogos, nos encontramos que actualmente hay una falta de paradigmas en los que nos podamos apoyar. Por ejemplo, un estructuralista sabía que cuando investigaba, tenía detrás una escuela muy fuerte, con un discurso bastante bueno. Vemos que nosotros a la hora de hacer trabajo de campo, situándonos en una antropología periférica, es más complejo. De cara al futuro, ¿usted qué consejo daría a los estudiantes y a los futuros antropólogos?

C.E.: Bueno, yo sólo puedo aconsejar el entrenamiento en las seis ramas; sólo puedo aconsejar eso. La antropología social, la etnología, la etnohistoria, la antropología física... Ahora saldrá un libro mío pensado en forma de preguntas y

\footnotetext{
${ }^{8}$ Se refiere a Carlos Castaneda, que en 1968 publicó el polémico trabajo sobre chamanismo, Las enseñanzas de Don Juan.
} 


\section{perifèria}

Número 14, abril 2011

www.periferia.name

respuestas. Yo mismo me hago las preguntas, pero digo que me las han preguntado los alumnos y las respondo. En el libro lo expresivo es un significado. Y lo que uno significa puede ser un símbolo, puede ser una estructura de parentesco, puede ser un sistema de valores... Ya he dicho al principio que no hay límite para un antropólogo. Porque si la antropología es el estudio del hombre, pues evidentemente el hombre no sólo hace parentesco, ni sólo hace dieta, ni sólo hace religión, o ideología. No. Yo creo que la antropología en este momento tiene un puñado de problemas. Y uno de estos problemas es el de qué es lo que debe hacer. El antropólogo una vez ya tiene un título, en primer lugar debe hacer una etnografía. Este es el entrenamiento básico. Y lo tiene que hacer en forma de una pretensión holística. Es decir, que no se entretenga en estar un mes y tome las notas y se vaya. No, esto no es un trabajo de campo. El trabajo de campo que habitualmente hacía el antropólogo era un trabajo de cómo mínimo un año. Porque las poblaciones humanas suelen tener en cuenta las temporadas de frío, calor, primavera, otoño; suelen tenerlo en cuenta.

Había antropólogos que no sólo estaban un año en el campo. Quizás se estaban cuatro años, como el caso del Malinowski. Él trabajó cuatro años en las Trobriand durante el tiempo que duró la guerra; estaba allí confinado y no tuvo más remedio. Pero este es el tipo de modelo Malinowski. Nosotros lo hemos tenido durante mucho tiempo como el modelo, pero no un modelo decisivo. Estamos hablando de una persona que vive con la gente. Yo creo que el trabajo del antropólogo termina en el momento en el que ya es como el otro. Este es el trabajo del antropólogo, aprender a vivir como el otro. Y eso no lo están practicando los antropólogos actuales. Incluso hay antropólogos que ya empiezan a hacer juicios sobre el tipo de forma de vida que hace otro. Escúchame, no te hemos llamado para que nos digas qué debe hacer este hombre o esta mujer; te hemos llamado para que nos digas cómo es este hombre y esta mujer. Para esto te hemos llamado, para tener un conocimiento.

Debemos procurar que se trabaje el conocimiento en la dirección teórica de la comparación etnográfica. Es decir, cuando usted tenga un conocimiento, cuando ya sea como el otro, usted ha quedado despojado de su ámbito original de socialización porque se ha socializado dentro de las categorías del otro. Entonces son estas categorías las que son significativas, las que funda el otro, no las que fundo yo. Las que fundo yo, es una manera de hacer antropología donde el otro 


\section{perifèria}

Número 14, abril 2011

www.periferia.name

queda muy desmejorado. Porque nos atrevemos a hablar de la teoría de fulano, de la teoría de mengano; y que tiene que ver con la teoría de Marx o la teoría de Freud. Yo ahora estoy haciendo una artículo sobre los huichol ${ }^{9}$ pero, oiga: ise sentirá bien en ella el huichol? ¿Se sentirán incorporados con lo que hice? En cambio hay antropólogos que sí que aprenden a decir cómo son los demás después de estar mucho tiempo en el campo, porque ellos también ya son otro cuando hablan, cuando escriben...

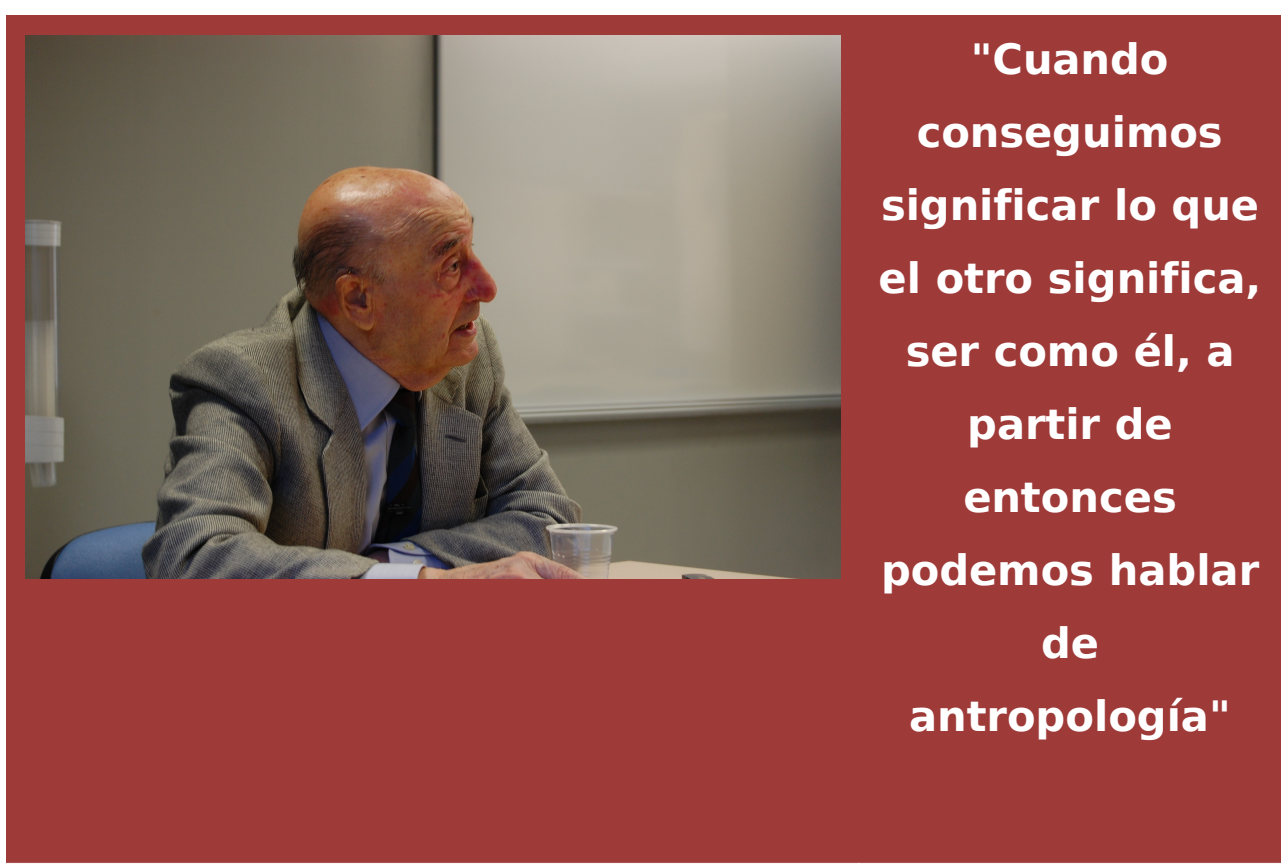

Yo pienso que ahora la antropología va hacia la fenomenología. Y la filosofía de la ciencia ha dicho muchas cosas sobre la fenomenología; es la manera más práctica de contestar a la gente que te contrata. Porque la gente que te contrata no quiere saber quién es el otro; lo que quiere es que le digas lo que tiene que hacer. $Y$ hasta qué punto uno se le parece $y$, asemejándose, si son iguales. Yo creo que el problema de la diferenciación es un problema muy importante actualmente dentro del trabajo del antropólogo. El problema está en la diferenciación.

Luego hay una orientación que yo creo que acabará dominando por lo menos sectores muy importantes, que es la cognición: la antropología que llamamos cognitiva. Se trata de una antropología que se origina en la lingüística y que luego

\footnotetext{
${ }^{9}$ También conocidos como wixarikas, son un grupo indígena del oeste central de México.
} 


\section{perifèria}

Número 14, abril 2011

www.periferia.name

se encamina hacia el neuropsiquismo. Esto lo quiero hacer entrar en México; ya he hablado con la gente que se tienen que orientar hacia el neuropsiquismo, dada la influencia que yo tengo del psicoanálisis. No lo practico, pero tengo mucha influencia de este tipo. Ahora, el psicoanálisis es individualista y nosotros trabajamos conjuntos sociales, poblaciones enteras. Entonces el neuropsiquismo nos puede dar lo que llamaríamos la información sobre lo que es un neuropsiquismo y sobre cómo se configura un neuropsiquismo en un individuo. Y hasta qué punto este neuropsiquismo está en relación con una configuración donde la mayor parte de los elementos que la forman son aproximadamente iguales. Es decir, podríamos hablar en términos de porcentajes, pero el porcentaje cualitativamente no nos sirve, salvo si nos proponemos hacer cualitativos los porcentajes sociales de la cultura. Entonces, todo esto plantea problemas. Yo creo que el antropólogo debe plantearse problemas y resolverlos.

Me planteo el problema de hasta qué punto el individualismo del antropólogo es positivo. Es fácil observar que el antropólogo es individualista y forma parte del mundo individualista. Por eso tiene tanto éxito ahora. Porque en realidad es el triunfo del individualismo a partir del capitalismo. Es la antítesis del socialismo. Este procuraba la igualdad, el esfuerzo hacia la igualdad. Y el individualismo no; este practica la idea del triunfo personal. De modo que en una plaza que hay se presentan dos cientos y gana uno, pero todo el mundo es competitivo. Esta es la versión que vivimos en éste momento: la competición, la crítica, el análisis, la ansiedad, las frustraciones y las neurosis competitivas; todo esto.

Yo soy de los que creo que en este momento se debe trabajar en la dirección de ser como es el otro. $Y$ el tiempo que tarde en conseguirlo uno, este es el tiempo que habrá hecho una antropología. Que quiere decir: primero una etnografía. Y después de esta, las significaciones que dan los indígenas, los aborígenes, los - digamos - los propietarios de una cultura; a qué elementos dan significación. Malinowski daba significación al kula. Para él este era la significación principal. Ruth Benedict pensaba en lo que había dicho Nietzsche sobre lo dionisíaco. Kardiner sobre la estructura de personalidad básica, sobre el estudio de la socialización. Es decir, los elementos que configuran las estructuras de la personalidad de una población son elementos comunes a todos los individuos a través de la socialización infantil. A través de la socialización infantil es cuando nosotros estamos en condiciones de hablar de una estructura de personalidad básica, que es la estructura que resulta 


\section{perifèria}

Número 14, abril 2011

www.periferia.name

del hecho de que no tenemos desarrollada la autonomía motora. Y como no tenemos desarrollada la autonomía motora, lo que hacemos es transmitir en estas criaturas las técnicas de cómo vivir correctamente; le transmitimos la información que tenemos los padres, la información que tiene la sociedad. Y así es como se configura una estructura de personalidad.

De modo que para mí la socialización es un estudio que no tienen los antropólogos y que, sin embargo, es la clave de la explicación. Y así, cuando conseguimos esto, significar lo que el otro significa, hacernos como el otro, cuando ya conseguimos esto, es evidente que a partir de aquí podemos hablar de antropología, de un profesional de la antropología. Porque la verdad es que los demás francamente más bien lo intentan, pero no lo veo. Yo, este es el consejo que le daría.

P: Muchas gracias profesor Esteva, ha sido una clase magistral. Le estamos muy agradecidas por habernos dedicado este tiempo y por compartir con nosotros sus experiencias y sus conocimientos.

C.E.: Muchas gracias a ustedes por haberme invitado. 


\section{perifèria}

Número 14, abril 2011

www.periferia.name

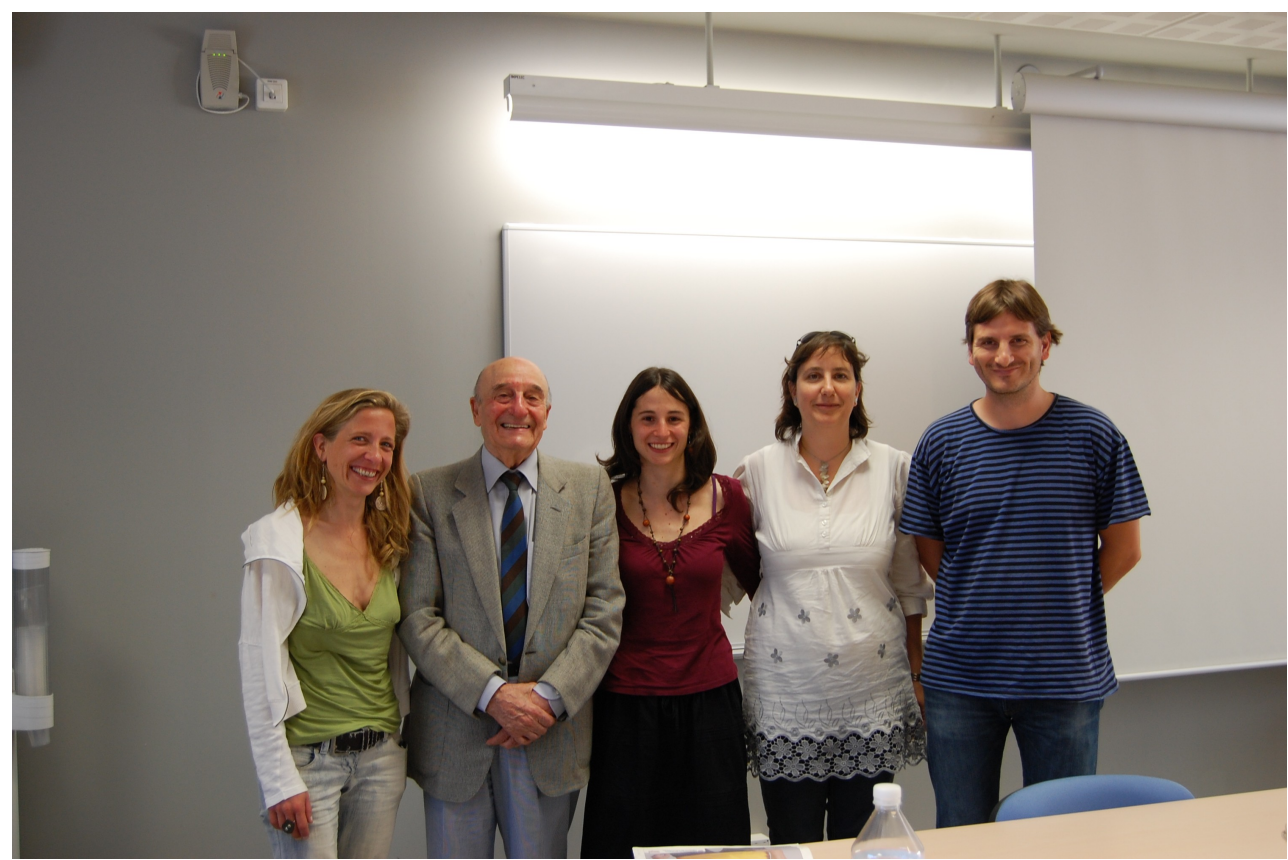

De izquierda a derecha: María Permanyer, Claudio Esteva, Janna Brufau, Montserrat Clua y Xavier Zulet

[Esta entrevista tuvo lugar la mañana del jueves 20 de mayo de 2010 en la sala de reuniones del Departamento de Antropología de la Universidad de Barcelona].

Agradecimientos: Al Doctor Claudio Esteva Fabregat por haber compartido con nosotras sus experiencias antropológicas y humanas, y a Montserrat Clua, por su paciencia y dedicación y por habernos dado esta gran oportunidad. 